\title{
THE SIGNIFICANCE OF NOTCHED UPRIGHT T WAVES
}

\author{
BY
}

\author{
WILLIAM DRESSLER, HUGO ROESLER, AND HENRIETTA LACKNER
}

From the Medical Services of the Maimonides Hospital, Brooklyn, New York, the Department of Medicine, State University of New York, and the Departments of Medicine and Radiology, Temple University Medical School and Hospital, Philadelphia, Pa.

Received March 29, 1951

Cardiological texts yield scant information on the significance of notching of upright $\mathrm{T}$ waves. White (1948) states briefly: "The T wave is frequently diphasic but rarely notched ... A late notch or dip in a low T wave in lead II suggests the effect of heart position in an otherwise normal person." Katz (1947) points out that notching of the $\mathrm{T}$ wave is abnormal in the limb leads but may be observed in records of normal children in leads CF2 and CF4, rarely in CF5. Occasionally, notching of $\mathrm{T}$ occurs in lead CF2 of normal adolescents. Pathologically notching of $\mathrm{T}$ is associated with hyperthyroidism or acute pericarditis. Scherf and Boyd (1946) mention the occurrence of bifid T waves in cases of rheumatic heart disease and pericarditis. According to Burch and Winsor (1949), notched T waves are not uncommon in lead II in normal persons; deeply notched T waves in lead I are suggestive of myocardial disease. Ashman and Hull (1941) state that the normal T wave is never abruptly and sharply notched; slight notching of low $\mathrm{T}$ waves in the limb leads and notched $\mathrm{T}$ waves in lead IV $\mathrm{F}$ are occasionally observed in normals; in heart disease due to rheumatic fever, thyrotoxicosis, arteriosclerosis, or syphilis, sharp notching of the $\mathrm{T}$ wave may be present, especially in lead IV F. Pardee (1941) writes: "Notching of T is rare in the limb leads. This wave is typically a smooth, rounded or peaked elevation, unless it should have a $P$ wave superimposed on it ... Notching of $T$ is seen ... as a result of digitalis and . . . quinidine administration. A similar notching has been observed in records from certain patients suffering from hyperthyroidism. Nothing can be said as to the significance of this notching of $\mathrm{T}$ except that it is probably due to a toxic reaction of the myocardium. Notching of $T$ is also found in records obtained by præcordial leads. It is much more frequently seen in these leads than in the leads from the extremities. Its significance in the præcordial leads is not understood but it is thought to be an abnormal finding.'

The statements quoted from current textbooks convey the impression that notching of $T$ is associated with few pathological conditions and that its meaning is still obscure. Within recent years we have become aware of the frequent incidence of notched $T$ waves, especially since we made it a routine procedure to take full sets of chest leads. We decided to study systematically the incidence and significance of notched $T$ waves correlating clinical and electrocardiographic data.

\section{MeTHODS AND RESUltS}

In a series of 1000 consecutive electrocardiograms obtained in the past two years from 333 hospital patients with and without heart disease, notching of the $T$ wave was found in the tracings of 54, representing 16 per cent of the total number of patients studied. All records included six chest leads and three unipolar limb leads in addition to the standard leads.

We analysed the clinical data of 100 patients who had been thoroughly studied by one of us 
during the past few years and whose electrocardiograms presented notched $T$ waves in limb or chest leads. A full set of leads was available in 74 cases of this series; CF, CR, and V leads were represented in fairly equal numbers. In 46 patients the unipolar limb leads were obtained.

The results of this study are recorded in Table I. The 100 cases that presented notching of $T$ included 13 without evidence of heart disease, and 87 that showed symptoms and signs of cardiac pathology.

TABLE I

InCidence of Notching of T in One Hundred Clinical Cases

\begin{tabular}{|c|c|c|c|c|c|c|c|c|c|c|c|c|c|}
\hline \multirow{2}{*}{ Heart condition } & \multirow{2}{*}{$\begin{array}{c}\text { Number } \\
\text { of } \\
\text { cases }\end{array}$} & \multicolumn{12}{|c|}{ Incidence of notching of $T$ in limb and chest leads } \\
\hline & & $\mathbf{I}$ & II & III & aVR & aVL & aVF & $\mathrm{Cl}$ & $\mathrm{C} 2$ & $\mathrm{C} 3$ & $\mathrm{C} 4$ & C5 & $\mathrm{C} 6$ \\
\hline 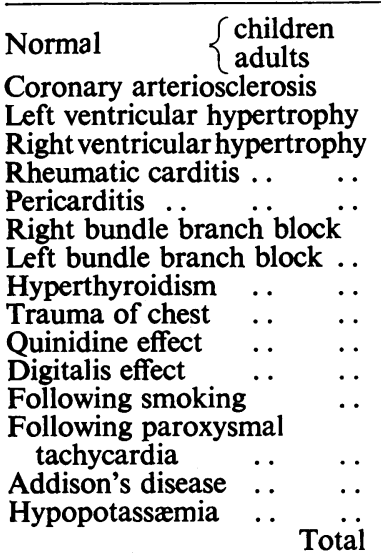 & $\begin{array}{r}6 \\
7 \\
32 \\
23 \\
1 \\
5 \\
4 \\
6 \\
3 \\
3 \\
1 \\
3 \\
1 \\
1 \\
1 \\
1 \\
2 \\
100\end{array}$ & $\begin{array}{l}\frac{-}{10} \\
\frac{-}{4} \\
\frac{2}{z} \\
\overline{-} \\
1 \\
\frac{1}{-} \\
- \\
1\end{array}$ & $\begin{array}{r}1 \\
1 \\
4 \\
\frac{1}{3} \\
\frac{1}{-} \\
\frac{1}{1} \\
\frac{1}{-} \\
- \\
- \\
11\end{array}$ & $\begin{array}{l}\bar{z} \\
\frac{1}{2} \\
= \\
= \\
\bar{z} \\
= \\
= \\
= \\
\bar{z}\end{array}$ & $\begin{array}{l}\frac{-}{1} \\
\frac{-}{1} \\
\bar{z} \\
\bar{z} \\
\bar{z} \\
= \\
\frac{-}{2}\end{array}$ & $\begin{array}{l}\frac{-}{2} \\
\frac{-}{2} \\
= \\
= \\
= \\
= \\
= \\
= \\
\frac{-}{4}\end{array}$ & $\begin{array}{l}\overline{-} \\
1 \\
1 \\
\bar{Z} \\
\bar{z} \\
\overline{-} \\
\bar{Z} \\
\bar{Z} \\
\overline{-} \\
\overline{1} \\
3\end{array}$ & $\begin{array}{l}\frac{2}{3} \\
\frac{1}{1} \\
= \\
= \\
\bar{Z} \\
\overline{1} \\
= \\
\overline{-} \\
\overline{-}\end{array}$ & $\begin{array}{r}3 \\
6 \\
12 \\
1 \\
1 \\
\frac{2}{2} \\
2 \\
1 \\
1 \\
- \\
1 \\
1 \\
31\end{array}$ & $\begin{array}{r}-1 \\
14 \\
5 \\
1 \\
4 \\
2 \\
2 \\
1 \\
1 \\
- \\
1 \\
-1 \\
33\end{array}$ & $\begin{array}{r}1 \\
1 \\
17 \\
13 \\
1 \\
2 \\
2 \\
2 \\
1 \\
1 \\
1 \\
1 \\
1 \\
1 \\
1 \\
1 \\
46\end{array}$ & $\begin{array}{c}\overline{-} \\
\overline{9} \\
1 \\
\overline{1} \\
\overline{-} \\
\overline{2} \\
\overline{1} \\
\overline{1} \\
1 \\
\overline{1} \\
1 \\
16\end{array}$ & $\begin{array}{l}\bar{Z} \\
\overline{3} \\
\bar{Z} \\
\bar{Z} \\
\overline{7} \\
\frac{1}{1} \\
\overline{1} \\
- \\
\overline{-} \\
\frac{1}{6}\end{array}$ \\
\hline
\end{tabular}

The normal group. The group of patients without evidence of heart disease included six children and seven adults. Notching of $T$ was infrequently observed in the limb leads; it occurred twice in lead II, once in the tracing of a child and once in an adult. In the præcordial leads, notching of $\mathrm{T}$ was more frequent; it occurred in tracings of children and adults in leads from positions $\mathrm{Cl}$, $\mathrm{C} 2, \mathrm{C} 3$, and $\mathrm{C} 4$. In three normal adults, who presented notching of $\mathrm{T}$, a diagnosis of neurocirculatory asthenia was made. One adult patient died of carcinoma of the csophagus; the post-mortem report stated that the heart was "perfectly normal." In this case the electrocardiogram showed notching of $\mathrm{T}$ in lead $\mathrm{C} 2$.

The pathological group. The group of patients with evidence of heart disease, whose electrocardiograms showed notching of $\mathrm{T}$, included a great variety of pathological conditions: Coronary arteriosclerosis (32)*; left ventricular hypertrophy (23); right ventricular hypertrophy (1); rheumatic carditis (5); pericarditis (4); right bundle branch block (6); left bundle branch block (3); hyperthyroidism (3); chest trauma (1); quinidine effect (3); digitalis effect (1); rapid effect of smoking (1); effect of prolonged paroxysmal tachycardia (1); Addison's disease (1); and hypopotassæmia (2).

Patients with heart disease showed notching of the $T$ wave rather commonly in the limb leads and even more frequently in the præcordial leads. Notched T waves were observed in lead I in 19 patients; in lead II in 12 patients; they were infrequently encountered in lead III and in the unipolar limb leads. In the chest leads the incidence of notching of $\mathrm{T}$ was highest in leads from positions $\mathrm{C} 2, \mathrm{C} 3$, and $\mathrm{C} 4$, which usually include the transitional zone; in lead $\mathrm{C} 2$ notching of $\mathrm{T}$ was present in 22 patients, in lead $\mathrm{C} 3$ in 32 patients, and in lead $\mathrm{C} 4$ in 44 patients.

* The figures in parenthesis indicate the number of cases in which the pathological heart condition was diagnosed. 
A striking parallelism can be observed in the incidence of notching and inversion of the $T$ waves. In electrocardiograms of normal children inversion of $T$ is frequently present in those præcordial leads displaying the right ventricular pattern (Goldberger, 1946); notching (or slurring) of $T$ is common in the same leads (Fig. 1). In adults with normal hearts, inversion of $\mathrm{T}$ is rare in leads $\mathrm{I}$ and II, and in the præcordial leads except from position $\mathrm{Cl}$; notched $\mathrm{T}$ waves are also unusual in these leads. Inversion of $\mathrm{T}$ in lead II and in the præcordial leads has been reported in instances of neurocirculatory asthenia (Graybiel and White, 1935); in 3 patients of the normal adult group of our series presenting notching of $\mathrm{T}$, the diagnosis of neurocirculatory asthenia was made.

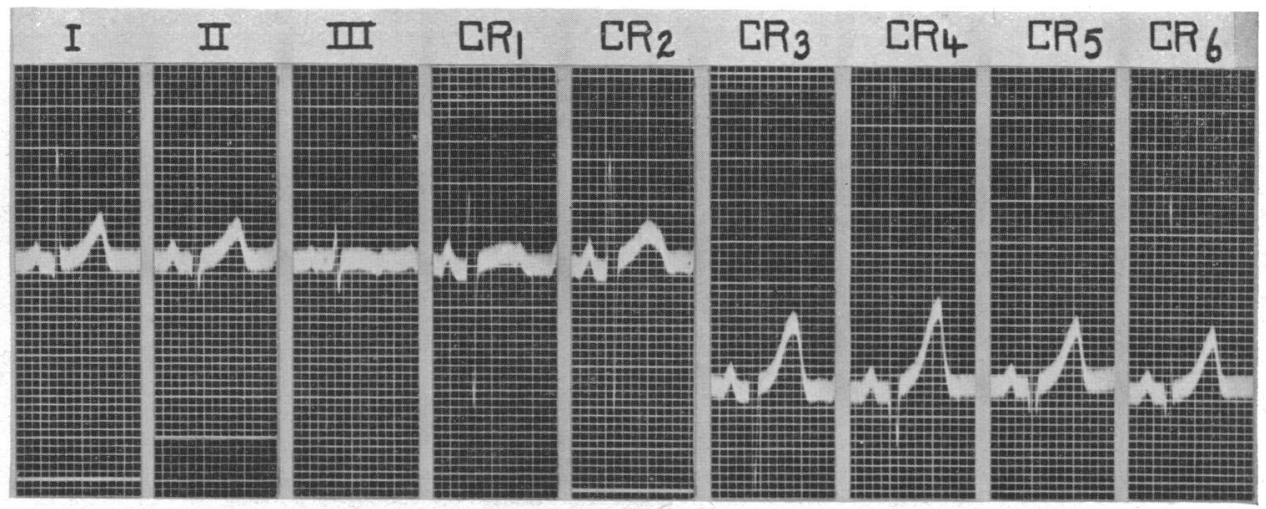

FIG. 1.-Five-year-old healthy child. The $T$ wave is notched in CR1. There is slurring of the descending limb of $\mathrm{T}$ near the apex in lead CR 2.

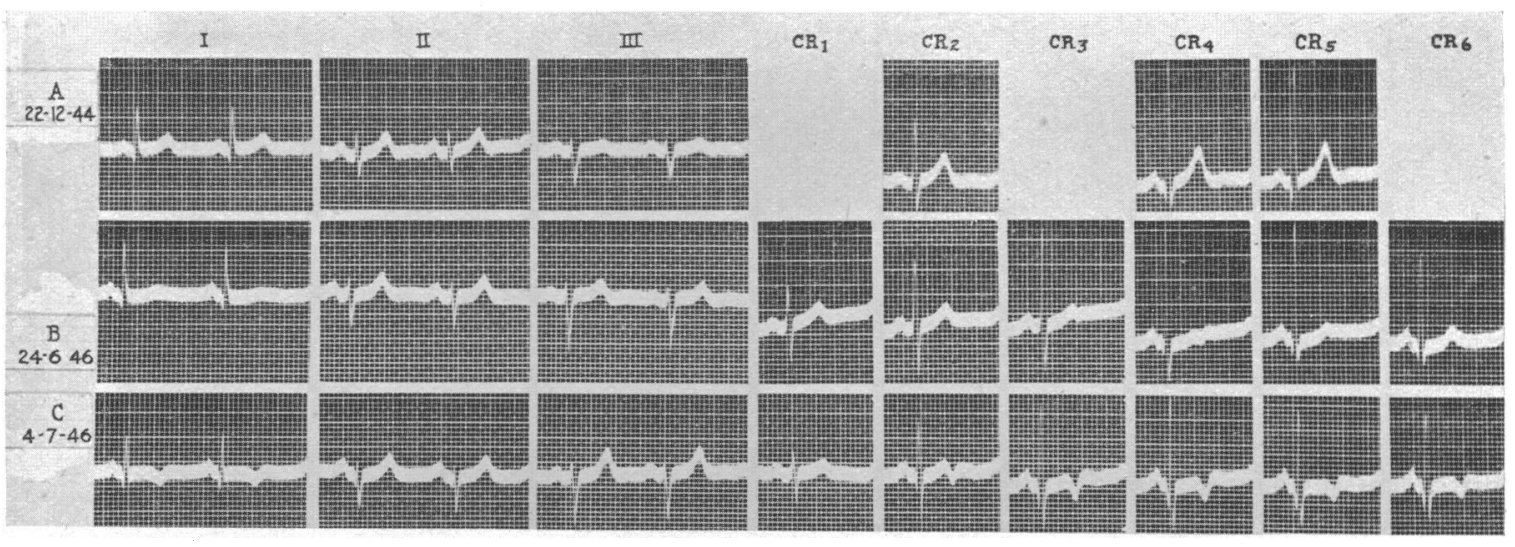

FIG. 2.-Fifty-eight-year-old man. (A) Before coronary attack. The tracing is normal. (B) Twenty-four hours after the onset of a protracted attack of substernal pain. T1 is low. There is notching of T in leads CR3 to CR6. (C) Twelve days after (A). Notching of T has turned to inversion in leads CR3 to CR6; besides, inversion of $T$ has developed in leads I and in CR2. (From Dressler and Roesler (1948). Amer. Heart J., 36, 115.)

Even more striking is the parallelism in the incidence of inverted and notched $\mathrm{T}$ waves in patients with heart disease. The variety of pathological conditions represented in our patients whose tracings showed notching of $T$ is identical with those heart diseases in which inversion of $T$ is a common finding. Ischæmia of the myocardium, above all, is often marked by notching as well as inversion of T. These electrocardiographic changes may be the only significant findings in these instances of acute coronary insufficiency where, following severe or prolonged anginal pain, evidence of myocardial infarction fails to develop (Fig. 2 and 3). Left ventricular hypertrophy ranges next to coronary 


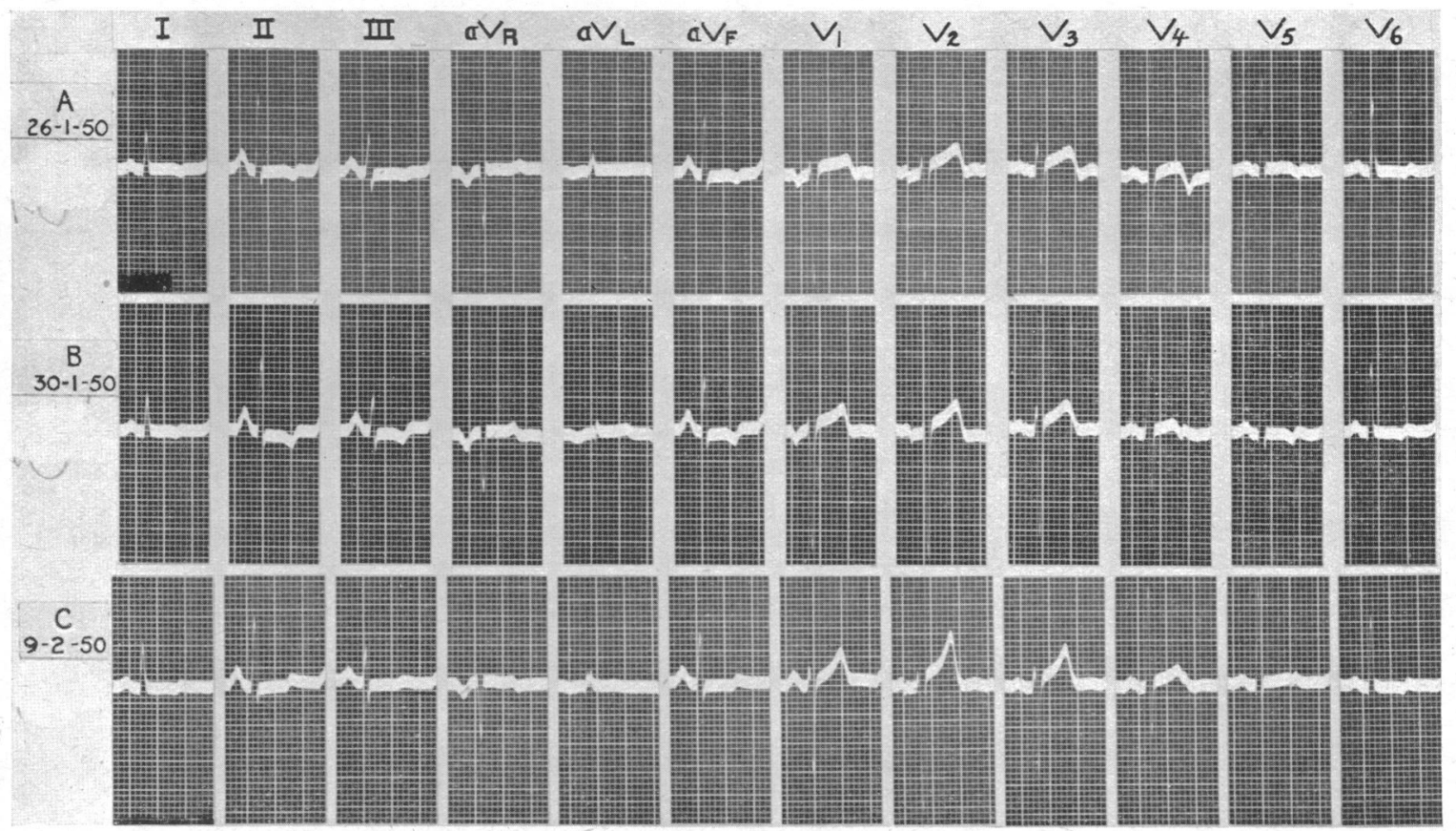

FIG. 3.-Fifty-year-old man. Hypertension. Exertional præcordial pain for the past five years. (A) Two and a half hours after the onset of a protracted attack of substernal pain. The $T$ wayes are inverted in the standard limb leads, in leads aVF and V5, and are semi-inverted $(\mp)$ in lead V6. There is terminal inversion of $\mathrm{T}$ in leads V1 to V4. (B) Four days after (A). In the leads V1 to V4 the changes of T are regressive. The $T$ waves have become upright in V1, V2 and V3, and are notched in lead V4. (C) Two weeks after (A). There is still slight notching of T in V4. Notching has replaced inversion of T in lead V5. In the præcordial leads from the right side, the amplitude of $\mathrm{T}$ has increased.

arteriosclerosis in the frequency of incidence of notched and inverted $T$ waves.

Notching and inversion of $\mathrm{T}$ are often present in the same tracing, especially in the chest leads. When inversion of $\mathrm{T}$ is confined to leads from the right or left side of the præcordium, notching of $\mathrm{T}$ is frequently present in the leads of the transitional zone. This is true, for instance, of preponderant right or left ventricular hypertrophy (Fig. 4) and bundle branch block. Occasionally notching and inversion or semi-inversion of $T$ are observed even in the same lead (Fig. 5, lead V2).

In acute conditions as in pericarditis or coronary insufficiency, transitions from notched to inverted $T$ waves may be observed in serial tracings (Fig. 2); or, the reverse course takes place in the healing stage, inversion of $\mathrm{T}$ being followed by notching before the $\mathrm{T}$ waves revert to normal (Fig. 3 ). Similar observations have been reported in experimental studies. Bayley and La Due (1944) studied the immediate effect of subtotal ligation of a coronary artery in continuous records. An elastic ligature was placed around the dissected artery and subtotal occlusion was carried out in stages by gradual tightening of the ligature, each stage lasting about thirty seconds. The first effect of ischæmia was notching at the top of the T waves (their Fig. 2) and then, while the loop round the coronary artery was tightened, the dip at the top of $T$ deepened until complete inversion of $T$ resulted. Hellerstein and Leibow (1950) produced in the dog inversion of $T$ in epicardial leads by cooling of the epicardial surface; notching of the originally upright $\mathrm{T}$ waves preceded the development of complete inversion of T. In man, Alzamaro-Castro et al. (1949) caused inversion of spontaneously notched $\mathrm{T}$ waves by carotid sinus pressure.

These clinical and experimental observations indicate that notching and inversion of $T$ are closely related and, indeed, have the same meaning. Inversion of $T$ points to a disturbance in the relative rapidity of the repolarization process in the subendocardial and subepicardial lamina of the 
myocardium (Hellerstein and Liebow, 1950). Notching of $\mathrm{T}$ is due to a disturbance similar in kind and different only in degree from that manifested in complete inversion of the $T$ wave. In semidirect and indirect leads, notching of $T$ may be also due to fusion of positive and negative potential changes derived from different portions of the myocardium. This mechanism may be responsible for notching of $T$ in the transitional zone of the præcordial leads when the $T$ waves in the extreme right and left side præcordial leads show opposite direction (Fig. 4).

\section{Slurred, Flat-TopPed, and Triphasic T Waves}

In tracings that exhibit notching of $T$, there are often related changes such as slurred, flattopped, or triphasic $\mathrm{T}$ waves. Notching of $\mathrm{T}$ is spoken of when the trace displays more than one 


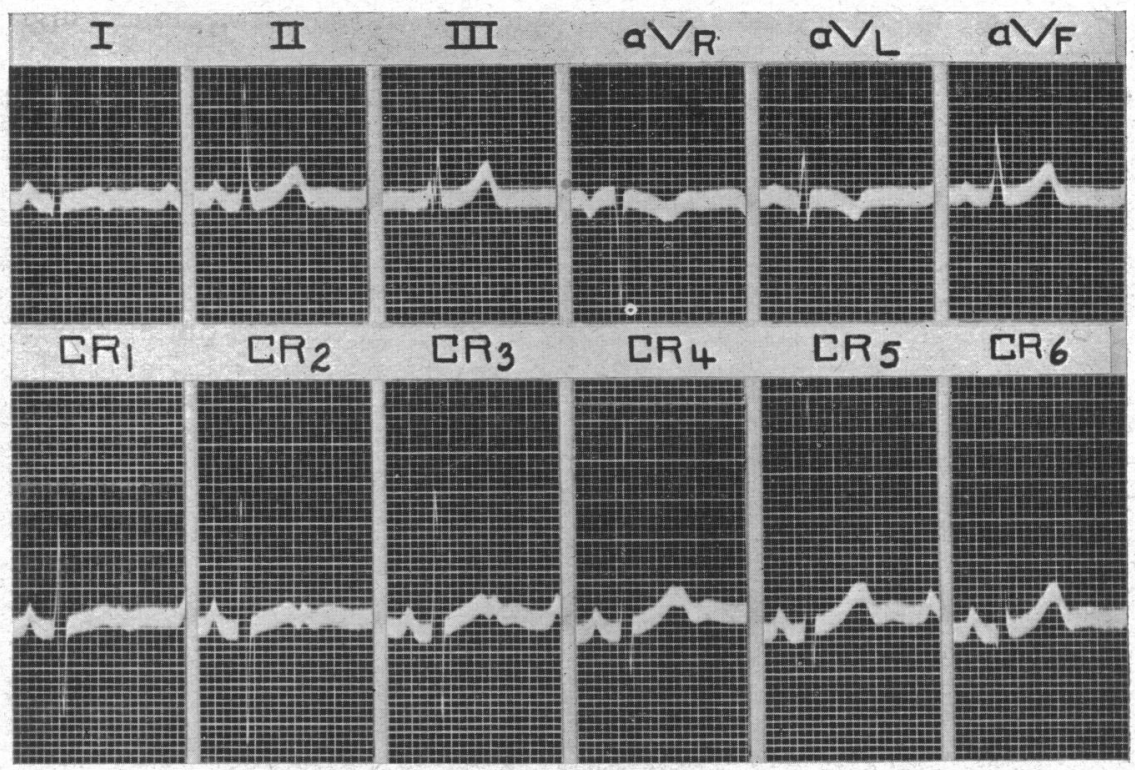

FIG. 6.-Nine-year-old child. Acute rheumatic fever. T1 is low and triphasic. The $T$ waves are notched and saddle-shaped in leads CR1 through CR3; they are flat-topped in leads CR4 and CR5. In lead CR3 the descending limb of T is fused with an upright $\mathrm{U}$ wave.

turning point at the same side of the reference level. When, however, instead of a change in direction, a sudden change in the rate of the rising or falling trace takes place, local thickening, i.e. slurring of $\mathrm{T}$ results (Fig. 1, lead CR2).

Notching of $\mathrm{T}$ may be located on the ascending or descending limb or at the apex of $\mathrm{T}$. In the latter case the top of the $T$ wave is wider than usual and may present a saddle form (Fig. 6). When the dip of the saddle deepens so as to reach below the level of reference, a triphasic $T$ wave is formed. On the other hand, the dip may be shallow or hardly noticeable; the $\mathrm{T}$ wave then appears flat-topped, presenting a plateau instead of a blunt or slightly rounded apex. Transitions from one type of change into the other are sometimes present in the same tracing (Fig. 6). Sagall et al. (1943), in experimental studies of the effect of quinidine, observed notching of $T$ which appeared one and a half hours after the ingestion of one gram of quinidine; before notching developed, the amplitude of the $T$ wave decreased and its top became flat and plateau-like.

Notched, slurred, flat-topped, and triphasic $T$ waves are closely related; they are apparently produced by a similar mechanism and have the same significance as inverted $\mathrm{T}$ waves.

\section{FALSE Notching of T}

False notching is due to superposition of a $\mathrm{P}$ or $\mathrm{U}$ wave upon a $\mathrm{T}$ wave. This possibility should be borne in mind whenever notching of $T$ is observed, since false notching differs profoundly in significance from genuine notching of $T$. The presence of a $P$ wave superimposed on $T$ is usually easily recognized. Fusion of a $U$ wave with $T$ can be diagnosed by comparing the length of the Q-T interval in such leads where notching of $T$ is absent, and then determining the end of the $T$ wave.

\section{SUMMARY}

The incidence and significance of notching of upright $T$ waves in clinical pathology was studied. Notching of the $T$ wave is a frequent electrocardiographic finding. In a review of 1000 electro$2 \mathrm{~K}$ 
cardiograms, that were obtained from 333 hospital patients with and without heart disease, notching of $\mathrm{T}$ was present in 16 per cent of the patients.

In the absence of heart disease, notching of $T$ is rare in the limb leads, but is not infrequent in præcordial leads especially in children. When heart disease is present, notching of $T$ is often observed in the limb leads and is even more frequent in the chest leads. It occurs in a great variety of pathological conditions, most often with coronary insufficiency and/or left ventricular hypertrophy.

Notching of $T$ is observed under the same conditions as inversion of $T$. Both features of $T$ may occur in the same lead either simultaneously or in serial tracings during the evolution of a pathological condition. Experimentally, certain effects such as progressive diminution of the coronary blood supply may produce first notching and then inversion of $T$. Thus, clinical and experimental evidence indicate that notching of $T$ is due to a similar mechanism and has the same significance as inversion of $\mathrm{T}$. Slurred, flat-topped, and triphasic $\mathrm{T}$ waves are closely related to notched $T$ waves and have the same meaning.

Genuine notching of $\mathrm{T}$ should be distinguished from false notching that is caused by superposition of $P$ or $U$ waves upon the $T$ wave.

\section{REFERENCES}

Alzamora-Castro, V., Rubio, C., Battilana, G., and Subiria, R., (1949). Amer. Heart J., $37,927$.

Ashman, R., and Hull, E. (1941). Essentials of Electrocardiography, 2nd ed., p. 158. McMillan Co., New York.

Bayley, R. H., and La Due, J. S. (1944). Amer. Heart J., 28, 54

Burch, G. E., and Winsor, T. (1949); A Primer of Electrocardiography, 2nd ed., pp. 93 and $95 . \quad$ Lea and Febiger, Philadelphia.

Goldberger, Emanuel (1946). Amer. J. Dis. Child., 71, 618.

Graybiel, A., and White, P. D. (1935). Amer. Heart J., 10, 349.

Hellerstein, H. K., and Liebow, I. M. (1950). Amer. Heart J., 39, 34.

Katz, L. N. (1947). Electrocardiography, 2nd ed., pp. 136, 169, 404. Lea and Febiger, Philadelphia.

Pardee, H. E. B. (1941). Clinical Aspects of the Electrocardiogram, 4th ed., p. 154. P. B. Hoeber, New York.

Sagall, E. L., Horn, C. D., and Riseman, J. E. F. (1943). Arch. intern. Med., 71. 460.

Scherf, D., and Boyd, L. J. (1946). Clinical Electrocardiography, 2nd ed., pp. 57, 68, 124. J. B. Lippincott, Philadelphia.

Wendkos, M. H. (1944). Amer. Heart J., 28, 549.

White, P. D. (1948). Heart Disease, 3rd ed., p. 207. McMillan Co., New York. 